\title{
Microglossia em bezerra
}

Carolina Dutra Minozzo $0^{[a]}$, Felipe Pohl de Souza ${ }^{[b]}$, Ana Paula Brenner Bush Becker ${ }^{[a]}$, Luiza Costa Barcellos ${ }^{[a]}$, João Henrique Perotta ${ }^{[a]}$, Ivan Roque de Barros Filho[a]"

\footnotetext{
[a] Departamento de Medicina Veterinária, Universidade Federal do Paraná (UFPR), Curitiba, PR, Brasil

[b] Médico veterinário
}

*Autor correspondente

e-mail: ivanbarf@ufpr.br

\section{Resumo}

Anomalias congênitas na língua de bezerros são raras, sendo as mais comuns a microglossia, protrusão lateral, anquiloglossia e língua dupla ou acessória. 0 primeiro relato conhecido de hipoplasia lingual congênita foi descrito em uma pessoa, na França, em 1719. Já nos bovinos, o primeiro relato dessa anomalia foi descrito no Irã, em 2007, em uma bezerra de aproximadamente três meses. A microglossia é o resultado da falha do desenvolvimento da língua no período embrionário. Nessa fase, a formação da língua se inicia pela proliferação da mesoderme na parte ventral do primeiro, segundo, terceiro e quarto pares de arcos faríngeos, a partir de tubérculos que incham e se fundem. Logo, a falha no crescimento dos inchaços pode originar malformações na língua. Anomalias congênitas podem estar relacionadas à presença de fatores teratogênicos durante a gestação, como agentes infecciosos, drogas, radiação, intoxicação por plantas e deficiências nutricionais, além da predisposição de algumas raças. 0 presente trabalho relata um caso de microglossia congênita em uma bezerra da raça Red Angus, oriunda de uma fazenda no município de Palmeira, Paraná, atendida no Hospital Veterinário da Universidade Federal do Paraná - UFPR, em junho de 2016. 0 animal de dez meses de idade pesava $52 \mathrm{~kg}$, apresentava caquexia e acentuado atraso de desenvolvimento, sialorreia, dificuldade na apreensão de alimentos, disfagia e fezes pastosas. De acordo com o proprietário, a bezerra apresentou dificuldade para mamar desde o nascimento. 0 diagnóstico de microglossia foi estabelecido pelo histórico do animal e exame físico. No hemograma e bioquímico clínico apenas a enzima gamaglutamiltransferase (GGT) encontrava-se aumentada. Após 17 dias de internamento, o animal veio a óbito por complicações de anaplasmose. À necropsia, não foram encontradas outras alterações além da microglossia. Por sua grande mobilidade, a língua desempenha importantes funções na apreensão de alimentos, deglutição, manutenção da higiene na cavidade oral e produção de sons. Por tanto, 
a sialorreia, dificuldade na ingestão de líquidos e alimentos e o atraso de crescimento são consequências da anormalidade do órgão. Nenhuma informação sobre a presença de fatores teratogênicos durante a gestação foi comunicada, mas a hipótese não foi descartada. Várias anomalias congênitas já foram descritas nessa raça de bovinos, mas microglossia não foi encontrada na revisão de literatura. Diferentemente de malformações corrigíveis cirurgicamente, como a anquiloglossia parcial, a microglossia é uma alteração sem tratamento e que limita a vida do animal. 